\title{
Violence, Empathy and Altruism: Evidence from the Ivorian Refugee Crisis in Liberia
}

July 2017

\begin{abstract}
In regions plagued by reoccurring periods of war, violence, and displacement, how does past exposure to violence affect altruism toward members of different ethnic or religious groups? Drawing on theories of empathy-driven altruism in psychology, we propose that violence can increase individuals' capacity to empathize with others, and that empathy born of violence can transcend group boundaries, motivating helping behavior toward ingroups and outgroups alike. We test this hypothesis using data on the hosting behavior of nearly 1500 Liberians during the 2010-2011 Ivorian refugee crisis in eastern Liberia, a region with a long history of cross-border, inter-ethnic violence. Consistent with our theoretical predictions, we find that those who experienced violence during the Liberian civil war host greater numbers of refugees overall, exhibit stronger preferences for distressed refugees and less bias against outgroup refugees, and host a higher proportion of non-coethnic, non-coreligious and distressed refugees. We further find that asking respondents to consider their own experiences with violence and displacement strengthens preferences for distressed refugees and reduces bias against non-coethnic and non-coreligious outgroups. These findings suggest that violence does not necessarily lead to greater antagonism toward outgroups, as is often assumed, and that in some circumstances it can actually promote inter-group cooperation.
\end{abstract}

Word count: 10335 


\section{Introduction}

In the past decade, more than 30 million people have fled their home country because of violence (UNHCR 2016). Globally, the total number of refugees is now more than 25 million, the highest it has been since the end of World War II. As humanitarian agencies and host-country governments struggle to meet the needs of historic numbers of displaced people, they have increasingly called on ordinary citizens to welcome refugees into their homes and communities through resettlement and local integration programs (UNHCR 2013). Building support for these efforts, however, is a daunting challenge. Particularly in developing countries, large inflows of refugees deplete scarce resources (Berry 2008; Betts and Collier 2017), exacerbate ethnic tensions (Gleditsch and Salehyan 2006), and increase the risk of civil conflict (Whitaker 2003).

Prior research shows that cultural ties and humanitarian concern play an important role in motivating individuals to welcome refugees despite the costs and risks associated with doing so (Bansak et al. 2016; Sturridge 2011). Conversely, a lack of cultural ties and ethnic divisions can make individuals reluctant to welcome refugees (Harild et al. 2013), particularly during times of economic scarcity. In this paper, we extend this literature by evaluating how past experience with violence influences individuals' willingness to host refugees. We focus in particular on how violence moderates the relative importance of cultural and humanitarian considerations.

Our analysis is motivated by the observation that the vast majority of refugees flee to countries or regions that experienced civil war or conflict in the past quarter century (UNHCR 2016). In these settings, many of those called on to host or otherwise assist refugees will have themselves been affected by violence and displacement in the recent past. Do these experiences make individuals less willing to assist refugees from ethnic or religious 'outgroups'? Or do they develop sympathies that transcend group boundaries and motivate helping behavior regardless of the ethnic or religious identity of those in need?

In considering these questions, we engage with a small but growing body of research on 
the social legacies of violence in regions recovering from conflict (e.g.Kijewski and Freitag (2016); Mironova and Whitt (2016); Wong (2016)). This literature offers two competing perspectives. First, consistent with theories of "parochial altruism" in psychology, several studies have suggested violence increases ingroup allegiance and hardens hostilities towards rival or potentially threatening 'outgroups' (Bauer et al. 2014; Beber et al. 2014; Rohner et al. 2013). Insofar as refugees come from ethnic groups that have previously been in conflict with local communities, or insofar as they heighten competition over scarce resources, activating a sense of group-based threat, this literature implies that prior exposure to violence will reduce support for outgroup refugees.

An alternative perspective links violence to potentially generalized improvements in altruism (Voors et al. 2012), community engagement (Bateson 2012; Bellows and Miguel 2009), and political participation (Blattman 2009). To account for these findings, these studies invoke the theory of post-traumatic growth (post-traumatic growth theory or PTGT), which posits a prosocial (re-)orientation of goals, priorities, and perspectives in the aftermath of traumatic events. However, how these changes might influence behavior toward refugees or other outgroups, however, remains unclear - the theory of post-traumatic growth does not address outgroup behavior, nor does it specify which motivations for prosocial behavior might be affected by violence, making it difficult to know. And because these studies largely come from settings where ethnic divisions are muted, it is possible that their results actually capture parochial rather than general prosocial behavior.

We address this gap by identifying empathy born of violence as a mechanism by which prior exposure to violence can motivate prosocial behavior. Drawing on psychological theories of empathy-driven altruism, we argue that violence can increase individuals' capacity to empathize with others, motivating altruistic behavior toward ingroup and outgroup others alike. Recognizing a similar experience of violence in others can create a bridging identity that motivates generous behavior across group boundaries. In contrast to theories of parochial altruism, our argument predicts that violence-affected individuals will be more 
responsive to humanitarian considerations and less responsive to material or cultural considerations when deciding whether to assist those in need.

We test this argument using data on the hosting behavior of nearly 1500 individuals during the 2010-2011 Ivorian refugee crisis in Liberia. During the crisis, more than 150,000 Ivorians fled into eastern Liberia, a region itself deeply affected by civil war from 1990-2003. With humanitarian actors unprepared and overwhelmed, Ivorian refugees were forced to find refuge in Liberian towns and villages. The ethnic composition of the refugees mapped onto salient ethnic divisions in Liberia: some shared ethnic and religious ties with the local population, others lacked cultural ties, and some came from groups that had a history of conflict with local communities.

We provide four main results in favor of the empathy born of violence hypothesis. First, we show that individuals who directly or indirectly experienced violence during the Liberian civil war host more refugees overall — including those co-ethnic to their wartime rivals. Second, we show that violence-affected individuals host a higher proportion of non-coethnic and Muslim refugees, as well as higher proportions of refugees who had health problems upon arrival or had fled direct violence. Third, we employ a conjoint experiment to show that although biases against outgroup refugees are strong overall, individuals who experienced violence exhibit less bias and have stronger preferences for refugees in distress. And fourth, by randomizing the survey module on past violence experiences to come immediately before or after the conjoint experiment, we show that preferences for the distressed are greater and outgroup biases are lower when individuals are primed to think about their own experiences with violence and displacement.

We also conducted a series of semi-structured field interviews to explore how Liberians reflected on their experience hosting refugees, finding that sympathies rooted in the shared experiences of hardship and displacement feature prominently in Liberians' reflections on the crisis. More broadly, we document overwhelming generosity toward refugees amid extreme resource scarcity, consistent with the idea that empathy born of hardship can motivate 
helping behavior across group boundaries, even in the presence of severe resource constraints.

This paper makes four contributions to existing research. First, we contribute to the literature on immigration, migration, and forced displacement, which despite the fact that more than 90 per cent of those forcibly displaced flee to developing rather than developed countries (UNHCR 2016), has hitherto focused largely on Western attitudes and behaviors towards refugees and asylum seekers. Moreover, while this literature highlights economic and cultural threat as important drivers of individuals' reluctance to support refugees or progressive immigration policies more generally (Adida 2014), it largely overlooks the potential for past experiences with conflict or hardship to overcome these concerns (Bansak et al. 2016; Brader et al. 2008). We speculate that empathy born of past experiences with conflict, displacement, and other hardships may underlie the impressive degree of hospitality toward refugees observed in many of the world's poorest countries as compared to wealthy countries, where hardships are less common.

We also contribute to the literature on post-traumatic growth, which has struggled to both pinpoint the mechanisms by which violence influences prosocial behavior and to discern whether or when these mechanisms motivate prosocial behavior between different social groups. Addressing these limitations, we build on PTGT and show that empathy born of violence can motivate altruistic behavior across group boundaries, even those hardened by wartime violence. Of course, our argument does not foreclose the possibility that violence may sometimes have parochial effects on prosocial motivation, as many have argued. Rather, we show that violence can also (and perhaps simultaneously) affect prosocial motivation in ways that bridge identity boundaries, and that in some settings, these countervailing effects can dominate.

This reasoning has important implications for our broader understanding of violence and prosocial behavior in diverse settings. In particular, it highlights the importance of understanding the potentially numerous mechanisms by which violence may influence behavior, and considering how each may (or may not) influence behavior in a given post-conflict set- 
ting. While impossible to generalize from the findings of a single study, our focus on empathy suggests the legacies of violence are relatively less likely to be parochial in situations where empathetic motivations for behavior are salient.

The third contribution of our study is empirical. Hitherto, identifying the effects of violence on intergroup behavior has been complicated by the difficulty of measuring intergroup behavior in post-conflict settings — or more specifically, by the fact that our ability to observe intergroup behavior is endogenous to how violence influences outgroup preferences. ${ }^{1}$ Prior research employs lab experiments to overcome these challenges, but these methods are subject to concerns about measurement validity, as several studies have shown that behavior in context-free experiments has no meaningful correlation with real-world behavior (Levitt and List 2007; Voors et al. 2012). Our study avoids these hazards by examining real-world (if self-reported) behavior in a setting where concerns about endogenous interaction are significantly ameliorated by forced displacement resulting from exogenous political developments in a neighboring country. We complement these measures with a survey experiment and an empathetic prime, showing consistent results across all three analyses. To the best of our knowledge, we are the first to show that violence can motivate prosocial behavior across group boundaries.

Lastly, our study provides important policy lessons for humanitarians and scholars concerned with helping the world's most vulnerable. In response to the growing incidence of protracted refugee crises and a push to avoid 'warehousing' refugees in crowded camps, humanitarian actors have increasingly turned to local integration (UNHCR 2013). This approach has also been seized upon as a way to offer support when refugee flows are variable or unpredictable and established refugee camps are unavailable. ${ }^{2}$ However, despite the chal-

\footnotetext{
${ }^{1}$ A notable exception is Hjort (2014)'s analysis of productivity among ethnically mixed and homogeneous teams in Kenyan flower plants as a function of temporal proximity to the 2007 Kenyan election crisis, when despite political turmoil and growing tensions between ethnic groups, workers were still obliged to go to work.

${ }^{2}$ See Polzer (2009) for a discussion of the politics limiting refugee camps (anti-
} 
lenges that policymakers face in building support for these policies (Bansak et al. 2016), there has been little research on what might motivate individuals to support this approach. Our results suggest that framing generosity towards displaced people in terms of shared experiences and common humanity may be effective at generating support for these and other progressive refugee policies.

\section{Violence, altruism, and support for refugees}

A large literature in political science and psychology suggests that conflict strengthens norms of ingroup allegiance and hardens hostilities towards rival or potentially threatening "outgroups" (Forbes 1997; Petersen 2011; Posen 1993; Sambanis and Shayo 2013). Consistent with this view, recent research at the micro-level documents a strong association between exposure to wartime violence, hostile attitudes toward outgroups, and prosocial behavior within but not between ethnic groups (Bauer et al. 2013; Beber et al. 2014; Rohner et al. 2013; Rozenas et al. 2017). ${ }^{3}$

While this literature has generally focused on behavior within war-torn countries, there are several reasons to expect the parochial legacies of violence to influence intergroup behavior during refugee crises. First and most generally, refugee crises often occur in regions where patterns of migration, trade, cultural exchange, and conflict transcend national boundaries. In these settings, national 'borders' are but one of the many factors that govern the scope of interaction between individuals, communities, and ethnic groups in the course of everyday life. As a result, in some circumstances the forcibly displaced may have little choice but to flee to regions where they have a history of antagonistic relations with local groups. In addition, in regions where national borders partition ethnic homelands, local communities may associate refugees with domestic groups with whom they have a history of conflict. Both dynamics were at play in our setting, as we discuss below.

warehousing) and the politics of local integration

${ }^{3}$ For an overview of this literature, see Bauer et al. (2016). 
Refugees may also introduce the threat of renewed conflict to the host population, activating a sense of group-based threat (Whitaker 2003). Gleditsch and Salehyan (2006), for example, show that refugees tend to increase the risk of conflict in host countries by spreading arms, altering the ethnic composition of host regions, and exacerbating competition over scarce resources.

And finally, there is evidence to suggest the parochial effects of violence may apply generally to all 'outgroups', regardless of their involvement in the conflict. Studying cooperative behavior in post-war Sierra Leone, Bauer et al. (2013) find that exposure to war has a lasting, positive effect on willingness to contribute to 'ingroups' from the same village despite having no effect on willingness to contribute to 'outgroups' from a distant village. ${ }^{4}$

\section{Violence and post-traumatic growth}

Not all research is pessimistic about the legacies of violence. A growing body of microlevel research shows that violence can lead to greater political participation (Bateson 2012; Blattman 2009), engagement in community activities (Bellows and Miguel 2009), and altruism (Voors et al. 2012). Many of these studies invoke the theory of post-traumatic growth to account for their findings, which posits positive change after highly challenging life crises or traumatic events that alter an individual's understanding of the world. According to this perspective, individuals' tend to undergo a period of intense cognitive processing and life-appraisal after trauma, leading to a renewed appreciation for life, an enhanced sense of personal strength, and greater pro-social orientation (Tedeschi and Calhoun 2004, p. 12).

In framing their results as evidence of 'positive' change after trauma, these studies implicitly assume that survivors' preferences for prosocial behavior are general rather than parochial. This may reflect the fact that post-traumatic growth theory is itself silent about

\footnotetext{
${ }^{4}$ Some research finds that priming subjects about past inter-group conflict reduces altruism to all groups, see Zeitzoff (2016).
} 
whether patterns of growth after trauma are parochial or general. ${ }^{5}$ It also may reflect the fact that studies linking violence to post-traumatic growth tend to come from homogeneous settings where identity boundaries are not particularly salient. Or it may simply reflect the difficulty of collecting data on intergroup behavior in post-conflict settings, where antagonistic groups are often segregated due to patterns of targeted displacement that may have occurred during the war (Balcells and Steele 2016).

But at a more fundamental level, uncertainty about whether patterns of prosocial growth after trauma are general rather than parochial may also be a consequence of the failure of existing theory to identify precisely which motivations for prosocial behavior are affected by hardship and how, since this makes it difficult to deduce whether such changes should promote cooperation across or within group boundaries. This gap in the literature is important because the distinction between parochial versus general changes in prosocial orientation has profound implications for patterns of recovery, reconciliation, and relapse after violence conflict.

In this paper, we address this gap by focusing on one specific psychological mechanism through which violence may influence intergroup cooperation: empathy. We argue that experiencing violence and trauma during war increases the capacity to empathize with others, and that such 'empathy born of violence' can in turn motivate altruism behavior across group boundaries.

While intuitive, our argument builds on post-traumatic growth theory in several important ways. Most notably, our argument is conceptually narrower and more precise than the theory of post-traumatic growth. Whereas post-traumatic growth specifies neither the psychological changes that lead to growth nor how they influence behavior in diverse settings, our theory of empathy born of violence identifies a specific psychological response to

\footnotetext{
${ }^{5}$ Of course, this limitation is understandable, given that they theory emerged from studies of survivors of car accidents, cancer, house fires, and other traumatic experiences in the U.S., where identity boundaries are relatively less salient (Calhoun and Tedeschi 2014).
} 
violence and explains how it in turns influences intergroup behavior in diverse settings. In addition, by virtue of its specificity about the operative mechanism, our argument provides clear implications regarding the conditions under which the legacies of violence are more or less likely to be parochial, as we discuss in the conclusion.

It is important to note, however, that while our argument about empathy born of violence is narrower and more precise that the theory of post-traumatic growth, the two are not incompatible. To the contrary, we suspect that empathy may contribute to the phenomenon of post-traumatic growth, and that some of behavioral patterns previously attributed to post-traumatic growth may be more precisely interpreted as evidence of empathy born of violence.

In the remainder of this section, we outline our argument in greater detail, starting with a discussion of empathy's constituent processes and their relevance to various forms of prosocial behavior.

\section{Violence, empathy and altruism}

While empathy may be particularly influential during refugee crises, it is also critical to a wide range of cooperative endeavors relevant to everyday matters. Often credited with helping to overcome social dilemmas associated with social insurance in "stateless" societies (Scott 1977), empathy is also an important complement to formal institutions. Individuals who are empathetic are more likely to voluntarily contribute to public goods and less likely to harm others for personal gain, reducing the need for institutional mechanisms of enforcement (Ostrom 2000). They are also more likely to contribute to state-led efforts to care for the downtrodden through co-productive arrangements such as fosterage or state-assisted hosting of refugees (Ostrom 1996).

Our argument linking violence to empathy builds on the theory of empathy-driven altruism (Batson and Powell 2003; De Waal 2008), which positions empathy as a primary 
driver of altruistic behavior. ${ }^{6}$ We propose that violence can motivate altruism across identity boundaries through the following steps: (1) conflict causes suffering among affected individuals and populations; (2) the experience of suffering increases empathetic capacity for others, particularly but not exclusively for those suffering from a similar experience; and (3) empathy transcends identity boundaries, thereby motivating altruistic behavior toward ingroup and outgroup others. In what follows, we first define empathy and establish how it motivates altruistic behavior, following (De Waal 2008); we then elaborate on each of the steps above.

According to De Waal (2008), empathy entails three processes, each of which motivates altruistic behavior. The first is emotional contagion (sometimes referred to as vicarious arousal), which occurs when a subject becomes emotionally distressed by the observation of another in need. Emotional distress motivates helping behavior egoistically — individuals help others so as to reduce their own emotional distress. The second is sympathetic concern, or "an affective response that consists of feelings of sorrow or concern for a distressed or needy other" (Eisenberg 2000, 677). Sympathy is other-oriented in that it involves feelings for the other, and thereby provides a genuinely other-regarding motivation for altruistic behavior distinct from egoistic motivations (Batson and Powell 2003, 274). The final process is perspective-taking, which refers to the cognitive ability to accurately perceive another's internal state. Perspective-taking reinforces emotional contagion by enabling the subject to comprehend the state of another in need, and can increase sympathetic responses as well (De Waal 2008, 285). ${ }^{7}$

\footnotetext{
${ }^{6}$ An alternative literature in psychology explores how hardship shapes empathy and in some contexts reduces it, see Li et al. (2013); Ruttan et al. (2015).

${ }^{7}$ There is debate as to which motivation is dominant and whether altruism is properly defined as such if motivated by egoistic concerns. For a review, see (Batson and Powell 2003, 485). The distinction is not relevant to our theory — what matters is that some components of empathy increase in response to experiences of hardship during violent conflict, be they emotional contagion, sympathy or both.
} 
The starting point of our argument is the observation that violence causes pain, hardship, trauma, and distress. These experiences promote empathy through several channels. The first is perspective taking. Hardship and suffering increase the capacity to understand another's condition, which amplifies the vicarious arousal and sympathetic components of empathy (Batson and Oleson 1991). A second channel is perceived similarity with those affected by violence (Staub and Vollhardt 2008). When subjects perceive another as similar, they are more likely to feel sympathy and provide assistance (Dovidio 1984; Karylowski 1976). A final channel operates through sympathetic capacity. When individuals have suffered hardship in their past, they are more likely to feel sympathy for those in need in general, independent of perceived similarity (Staub and Vollhardt 2008; Tedeschi and Calhoun 2004). This implies that hardship can increase empathetic-altruism toward others even if the context of their suffering is dissimilar to the one they experienced. That said, the effect of hardship on altruism should be larger when there exists a correspondence between experiences, given the added influence of enhanced perspective-taking and perceived similarity.

An important characteristic of empathy is its ability to transcend identity boundaries and motivate altruism toward outgroup others (Batson 1997; Shechter and Salomon 2005). There are several possible reasons for this. The capacity to feel sympathy for another's suffering cuts across group divisions, even if less sympathy may be felt for those of outgroup status (Dovidio 1984; Krebs 1975). The ability to empathize is enhanced by perspectivetaking, which does not depend on identity group status. To the extent that violence-affected individuals feel solidarity with those currently in need, the shared experience of violence may come to serve as a cross-cutting tie that bridges outgroup identities, just as cross-cutting economic or social ties counteract the salience of ethnicity (Dunning and Harrison 2010).

\section{Predictions}

Our argument provides three testable hypotheses, which are both general and applicable to refugee crises. First, we expect individuals who have experienced violence to be more likely 
to help those in need, relative to those who have not experienced violence. Second, when deciding who to help, violence-affected individuals should be more responsive to signs of distress and less responsive to the ethnic or religious identity of those in need. As a result, they should help a higher proportion of distressed and outgroup others, in addition to helping more overall.

\section{Setting}

We test these predictions using data collected shortly after the 2010-2011 Ivorian refugee crisis in Liberia. During the crisis, a diverse population of more than 150,000 refugees fled into eastern Liberia, seeking refuge from post-election violence in south-western Côte d'Ivoire. At the time, residents were still recovering from a civil war that devastated the region from 1990-2003. Against this backdrop, we assess how Liberians' past experiences with wartime violence influenced their support for refugees during the crisis.

This section provides background information on the crisis, focusing on its origins, the prevalence of cross-border ties in the region, the salience of ethnic divisions during the crisis, and the practicalities of hosting.

\section{Civil war in Côte d'Ivoire}

The origins of the conflict in Côte d'Ivoire date back to development policies adopted in the 1960s (Klaas 2008). Following independence from France in 1960, the government sought to foster development by aggressively promoting export led growth in the agricultural sector. Central to this strategy were policies that encouraged farmers from the northern and central regions of Côte d'Ivoire to immigrate to the fertile and sparsely-populated southwest, near the border with Liberia. In the ensuing decades, a steady supply of cheap, migrant labor along with favorable commodity prices made Côte d'Ivoire one of sub-Saharan Africa's most stable and economically successful countries. However, by the mid-1990s, population growth and 
reverse rural-to-urban migration following an an economic downturn lead to conflict between self-identified indigenous and migrant populations over increasingly scarce land (McCauley 2013).

This period of increasing land scarcity and economic hardship coincided with the introduction of multiparty political competition following the death of Félix Houphouët-Boigny, the country's long term President, in 1993. Over the course of the 1990s, ethno-regional divisions between the northern, central, and southern parts of the country came to dominate multiparty politics. The southwest emerged as a microcosm of the country's broader ethnopolitical divides and a hotbed for political violence, as politicians exploited land conflicts between indigenous and migrant groups to mobilize electoral support.

After nearly a decade of increasingly violent and divisive political rhetoric, a short civil war in 2002 divided the country in two, with rebels representing the country's northern and central blocks holding territorial control in the north and government forces loyal to Laurent Gbagbo, preferred leader of the country's southern regions, holding control of the south.

\section{Ivorian refugee crisis in Liberia}

After more than six years of UN-brokered peace talks, political leaders from the main factions agreed to honor the results of a national election scheduled for October 2010. Despite hopes of an end to the protracted civil crisis that had divided the country since 2002, the election sparked renewed violence when then-President Laurent Gbagbo refused to cede power to rebel-leader Alassane Ouattara following his defeat in the second round. In the ensuing months, fighting between supporters of Ouattara and Gbagbo would leave over 3000 dead and more than 300,000 displaced.

The fighting was particularly intense in south-western Côte d'Ivoire, along the border with Liberia. Long considered the epicenter of the crisis, armed groups from both sides perpetrated collective targeting based on ethnic identity, causing large numbers of civilians from both sides of the conflict to flee into eastern Liberia. 


\section{International response}

Despite warnings of election-related violence more than six months before the election (ICG 2010), the international community was poorly prepared to handle the crisis. The first refugee camps were not constructed until April of 2011, five months after refugees first entered Liberia. After the onset, refugee flows into Liberia remained variable and difficult to predict, making it difficult for relief agencies to know when and where their resources would be needed. And throughout the crisis, bad roads, heavy rains, and lack of infrastructure posed a persistent challenge to the response. With relief agencies unprepared and overwhelmed, refugees from both sides of the conflict were forced to seek refuge with local communities.

\section{Local integration of refugees}

The process of local integration was complicated by the ethnic and religious diversity of the refugee population and the long history of cross-border, inter-ethnic violence in the region. For refugees from ethnic groups with indigenous ties to the border region, strong cultural ties to the host population facilitated integration. ${ }^{8}$ These ties are grounded in both past experiences with displacement as well as ongoing patterns of economic and social life: 21 per cent of respondents report either buying or selling goods across the border, 76 per cent say they have friends across the border, and 79 per cent report visiting Côte d'Ivoire in the past month.

Refugees from so-called migrant groups, however, were dependent on the willingness of Liberians to host "strangers" with whom they had fewer ties. Muslim refugees from the Malinke ethnic group of northern Côte d'Ivoire were particularly vulnerable during this period. Many Liberian residents sympathized with non-Muslim coethnics across the border

\footnotetext{
${ }^{8}$ In our sample, for example, roughly 50 per cent of respondents had previously lived as refugees with co-ethnic host families in Côte d'Ivoire during the Liberian civil war, while a further 45 per cent of respondents reported that they knew at least some of the refugees that they hosted prior to the crisis.
} 
in what was framed as a struggle to defend their land from perceived encroachment by predominantly Muslim groups of northern Côte d'Ivoire. During both the 2002 and 2010 civil wars in Côte d'Ivoire, for example, fighters from the Krahn and Yacouba groups in Liberia fought alongside their coethnics in south-western Côte d'Ivoire. ${ }^{9}$ Yet even those who did not directly participate fighting often were intimately familiar with, and personally affected by, the Ivorian conflict, as nearly half of the residents in the region lived with co-ethnics across the border during their own exile.

In addition to sympathizing with their co-ethnics across the border, host communities have a long history of antagonistic relations with the Malinke ethnic group in Liberia. During the Liberian civil war, divisions between the Malinke and the host population - specifically members of the Yacouba and Guere ethnic groups — were responsible for some of the war's worst atrocities. ${ }^{10}$ Although Liberia has made important progress towards reconciling the divide between Christians and Muslims following the end of its war in 2003, these divisions remained salient at the time of the Ivorian refugee crisis. According survey data collected shortly before the crisis, for example, the Malinke were viewed as Liberia's most violent, least friendly, and least sanitary group. ${ }^{11}$

\section{Modalities of hosting}

When members of the host population did choose to offer their support, they did so in various ways. In this study, hosting a refugee is defined as welcoming a refugee family to "sleep under your roof and eat from your pot." Under this definition, 80 per cent of our sample hosted at

\footnotetext{
${ }^{9}$ For a review of the Liberian's role on the Ivorian conflict, see ICG (2003) and McGovern (2011).

${ }^{10}$ For a review of the Liberian civil war, see Ellis (2001).

${ }^{11}$ In particular, analysis of survey data collected by Blattman et al. (2014) in 2010, finds that 26 per cent of residents in our region identified the Malinke as the country's most violent ethnic group, while nearly 50 per cent of respondents described them as "likely to keep their place dirty."
} 
least one refugee. On average, respondents hosted 7.1 refugees for an average of 5 months. Other forms of support included providing meals, water, or temporary refuge to refugees on their way to other communities or refugee camps.

To find shelter, refugees walked from village to village until they found a Liberian family that was willing and able to host them. Often they would rest temporarily in a village, hoping that a local family might approach them with an offer of accommodation, or seeking help from a village authority who in turn may have looked for volunteers in the community to serve as hosts. NGOs sometimes facilitated the movement of refugees, offering to carry them to another village or, later in the crisis, to a newly constructed refugee camp.

Hosting was unlikely to have conferred material gains that outweighed the direct costs

of hosting. Ivorian refugees fled with little resources with which to remunerate hosts, and humanitarian providers were unable to adequately provide support to communities hosting refugees, resulting in significant strains on host community food supplies, sanitation facilities and water sources, and an early onset of coping strategies associated with the hunger season (Brady 2012). In our sample, only 6 per cent of respondents agreed that the refugees "brought benefits to your community", and only 15 per cent of refugee families remunerated their hosts, most commonly through farming (15 per cent) or NGO-provided rations (6 per cent).

\section{Research design}

\section{Sample}

We employ observational and experimental survey data from 64 Liberian villages in the Liberia - Côte d'Ivoire border region. Data were collected in collaboration with the Norwegian Refugee Council (NRC) as part of an evaluation of their programming in the region. Our sample consists of i) 32 villages selected by the NRC to receive an economic recovery 
program after the crisis, ${ }^{12}$ ii) 32 comparison villages selected using pre-treatment census data and Mahalanobois matching, and iii) 16 villages selected by the Government of Liberia to serve as "host villages", where refugees were encouraged to settle and aid agencies encouraged to channel their assistance efforts while more permanent camps were constructed. ${ }^{13}$ In Appendix 1, we use census data to show that villages in our sample are slightly larger than the remaining population of villages in the region but otherwise comparable on measures of wealth, education, and health. To ensure that sample selection does not bias our results, we use village fixed effects throughout our analysis.

The surveys were conducted in July 2013 and June 2014. In each community, we randomly selected 20 residents to participate via a random walk procedure. The survey covered background characteristics, hosting of refugees, experiences with displacement and violence during the Liberian civil war, and the conjoint survey experiment described below.

\section{Data}

\section{Survey data}

Our main dependent variables are as follows: Refugee-months hosted, calculated as refugee family size x duration of stay, summed across all families that were hosted; Hosted ethnic outgroup, an indicator for whether the respondent hosted an non-coethnic fam-

\footnotetext{
${ }^{12}$ The program, implemented between August 2013 and March 2014, sought to advance the economic recovery of host communities through the provision of agricultural tools and training.

${ }^{13}$ While this program may have had some effect on residents' hosting behavior, these effects should be limited because the program began in Spring of 2011, roughly five months after the start of the refugee crisis (when the need for resident's to host was most urgent), and because the program housed refugees in separate quarters, an arrangement excluded from our definition of hosting (having refugees "sleep under your roof and eat from your pot"). Regardless, our use of village fixed effects ensures that sample selection does not bias our results.
} 
ily; Hosted religious outgroup, an indicator for whether the respondent hosted noncoreligious family; Hosted family with health problems, an indicator for whether the respondent hosted a family that had health problems upon arrival; Hosted family w/ food insecurity, an indicator for whether the respondent hosted a family whose members were "hungry" or "starving" upon arrival; and Hosted family fleeing violence, an indicator for whether the respondent hosted a family that was fleeing direct violence. We also con-

sider the proportion of hosted refugees that i) were from ethnic and religious outgroups, ii) demonstrated health problems or food insecurity upon arrival, or iii) had fled direct violence.

Our main independent variable is exposure to violence during the Liberian civil war, which is measured as the sum of six indicator variables denoting whether the respondent ever experienced: beatings, the burning of their home, serious injury or maiming, serious injury to a family member, the death of a family member due to violence, or was witness to beatings, torturing or executions. The resulting variable, Violvict, has a mean of 2.6 and a standard deviation of 1.6. Alternative constructions using factor analysis or subsets of the input variables have no material effect on the results.

\section{Conjoint experiment}

We complement the survey data with a choice-based conjoint experiment designed to elicit respondents' preferences over attributes of refugees. Conjoint experiments allow researchers to determine how respondents value different attributes in the context of a specific choice. In the experiment, we ask respondents to imagine a new crisis in which the number of refugees seeking refuge is greater than the capacity of the community to host (much like actual refugee crisis). Respondents were then tasked with choosing one of two hypothetical refugee families whose attributes were randomly assigned across five dimensions: gender of the household head, ethnicity, religion, occupation, and whether the refugees were hungry, as summarized in Table 1. 
Table 1: Refugee Attributes Randomized in Conjoint Experiment

\begin{tabular}{rrr}
\hline Attribute & Level 1 & Level 2 \\
\hline Gender of HH & Male & Female \\
Ethnicity & Co-Ethnic & Not Co-Ethnic \\
Religion & Christian & Muslim \\
Occupation & Farmer & Not Farmer \\
Food & Have food & Do not have food \\
\hline
\end{tabular}

Each respondent successively evaluated three pairs of refugees. Because 50 per cent of respondents were illiterate, we used pictographs to display the attributes. The pictographs were designed to depict only the relevant attribute level while maintaining neutrality on other dimensions such as aesthetic appeal. Appendix 2 displays the pictographs as they were presented to respondents.

Our randomization procedure excluded co-ethnic, not co-religious profiles for respondents who belong to an ethnic group that is predominantly of one religion. This applies to about 30 per cent of our sample. ${ }^{14}$

We then analyze our respondent choice patterns to order to make inferences about the how specific characteristics, such as ethnicity or religion, affect hosting decisions. The randomization of attributes allows us to make unbiased estimates of how various attributes affect respondent choice.

\section{Semi-structured interviews}

To inform and validate our analysis with Liberians' own impressions of the crisis, we conducted 16 semi-structured interviews with community leaders in host communities. The interviews focused on their personal reactions to the crisis, community experiences during the crisis, the practicalities of hosting refugees, and the community discourse attending the

\footnotetext{
${ }^{14}$ For example, the Grebo of southern Côte d'Ivoire and eastern Liberia overwhelmingly identify as Christian. Accordingly, we excluded profiles in which a Grebo respondent is presented a co-ethnic, Muslim family.
} 
arrival of the refugees.

\section{Estimation}

We estimate the association between Liberians' past exposure to violence and their support for refugees via:

$$
Y_{i j}=\alpha_{j}+\gamma \text { Violvict }_{i j}+X_{i j}^{T} \beta+\epsilon_{i j}
$$

where $j$ denotes the village, $i$ denotes the individual, $X_{i j}$ is a vector of fixed and prewar covariates, ${ }^{15}$ and Violvict is the index of six violent experiences described above. The inclusion of village fixed effects $\left(\alpha_{j}\right)$ ensures that the association between violence and hosting behavior $(\gamma)$ is not driven by local or regional differences in levels of wartime violence; the inclusion of prewar covariates $\left(X_{i j}\right)$ ensures it is not driven by observable differences between individuals.

Interpreting $\gamma$ as causal then requires that the unobserved predictors of violence do not also influence hosting behavior. In Appendix 3, we argue that this assumption is consistent with historical accounts of the war, which highlight how limited information, low mobility, frequent shifts in territorial control, and erratic behavior by combatants limited the ability of citizens to avoid violence (Ellis 2001; Lidow 2011). We also show that violence is uncorrelated with most observed variables $\left(X_{i j}\right.$, above), and that those that do predict violence - prewar livestock ownership, prewar relations to village chief, and gender — are poor predictors of hosting behavior, and therefore unlikely to confound. Hence, insofar as unobserved predictors are similar to the observed predictors, they too are unlikely to confound.

However, as with all observational studies, we cannot rule out omitted factors entirely,

\footnotetext{
${ }^{15}$ Covariates include: five age cohort indicators, prewar family relation to chief, parental education, gender, ethnicity, prewar family livestock ownership, prewar family business ownership.
} 
and we take several steps reduce the likelihood that they account for our results. First, by testing an unusually extensive set of outcomes, each linked to a specific observable implication of our argument, we aim limit the set of confounders that could account for our results.

Second, we conduct a sensitivity analysis following Oster (2017) to assess how confounding omitted factors would need to be to account for our results. The intuition behind this approach is to use the bias eliminated by observed variables to assess the potential bias of unobserved, omitted variables. Substantively, we find that for every outcome in our main analysis (Tables 2 and 3, below), omitted factors would have to be considerably more confounding than observables to reduce effect sizes to zero (Appendix 3). We believe this is unlikely, and note that this level of robustness exceeds the conservative standards recommended by Oster (2017). Moreover, the analysis shows that coefficient stability and changes in R-squared values between our uncontrolled and controlled regressions are consistent with those of experimental studies, suggesting our conditional exogeneity assumption holds. Full details are provided in Appendix 3.

Our final strategy to guard against confounding factors is to use an empathetic prime to validate the observational analysis of violence and preferences. More specifically, we randomly assigned whether the survey module on past violence came immediately before or after the conjoint experiment. By increasing the emotional and cognitive salience of past experiences with violence, the module is likely to increase the core components of empathy — vicarious arousal, sympathy, and perspective-taking — during the selection exercise. We therefore expect the prime to influence preferences over refugee attributes in a similar manner to actual past violence behavior. 


\section{Results}

\section{Wartime violence and hosting}

Estimates of $\gamma$ from Equation 1, with and without $X_{i j}$, are presented in Table 2. The results show a robust relationship between past violence exposure and support for ingroup and outgroup refugees. Substantively, exposure to one additional act of violence associates with 5.6 additional refugee-months of hosting overall, a 2 percentage point increase in the likelihood of hosting non-coethnic refugees, and 1 percentage point increase in the likelihood of hosting non-coreligious refugees. ${ }^{16}$ While these figures may seem modest, they are not: they amount to a 10, 9, and 14 per cent increase relative each outcome's mean (reported in Table 2, Row 5).

Past experience with violence also associates with greater hosting of refugee families that were experiencing health problems or food insecurity upon arrival, as well as refugee families that fled direct violence. Substantively, one additional act of violence associates with a 5 percentage point increase in the likelihood of hosting a family that had health problems upon arrival, a 4 percentage point increase in the likelihood of hosting a family that was "hungry" or "starving" upon arrival, and 4 percentage point increase in the likelihood of hosting a family that fled direct violence. We view these latter results as particularly strong evidence in favor of the empathy born of violence argument, as they are not predicted by rival theories of violence and behavior. Importantly, coefficient estimates change little with the inclusion of additional controls, suggesting that selection into violence is unlikely to be confounding our results (Oster 2017).

\footnotetext{
${ }^{16} 91$ per cent of our sample is Christian, 1 per cent is Muslim, and 7 per cent practice a traditional religion.
} 
Table 2: Wartime violence and hosting of refugees

\begin{tabular}{|c|c|c|c|c|c|c|}
\hline \multirow[b]{2}{*}{$\begin{array}{l}\text { Violence } \\
\text { index }(0-6)\end{array}$} & \multicolumn{2}{|c|}{$\begin{array}{l}\text { \# Refugee Months } \\
\text { Hosted }\end{array}$} & \multicolumn{2}{|c|}{$\begin{array}{c}\text { Hosted } \\
\text { Ethnic Outgroup }\end{array}$} & \multicolumn{2}{|c|}{$\begin{array}{c}\text { Hosted } \\
\text { Religious Outgroup }\end{array}$} \\
\hline & $\begin{array}{c}\mathbf{5 . 8 5}^{* * *} \\
(1.31)\end{array}$ & $\begin{array}{c}\mathbf{5 . 5 8}^{* * *} \\
(1.43)\end{array}$ & $\begin{array}{c}\mathbf{0 . 0 2}^{* *} \\
(0.01)\end{array}$ & $\begin{array}{c}\mathbf{0 . 0 2}^{* * *} \\
(0.01)\end{array}$ & $\begin{array}{l}\mathbf{0 . 0 1} \\
(0.01)\end{array}$ & $\begin{array}{c}\mathbf{0 . 0 1}^{* *} \\
(0.01)\end{array}$ \\
\hline $\mathrm{R}^{2}$ & 0.25 & 0.30 & 0.22 & 0.34 & 0.08 & 0.20 \\
\hline Num. obs. & 1595 & 1318 & 1070 & 1053 & 1070 & 1053 \\
\hline Y Mean & 61 & 61 & .22 & .22 & .07 & .07 \\
\hline Village FE & $\mathrm{Y}$ & Y & $\mathrm{Y}$ & $\mathrm{Y}$ & $\mathrm{Y}$ & $\mathrm{Y}$ \\
\hline \multirow[t]{2}{*}{ Ctrl Vars } & $\mathrm{N}$ & $\mathrm{Y}$ & $\mathrm{N}$ & $\mathrm{Y}$ & $\mathrm{N}$ & $\mathrm{Y}$ \\
\hline & \multicolumn{2}{|c|}{$\begin{array}{c}\text { Hosted family } \\
\mathrm{w} / \text { health problems }\end{array}$} & \multicolumn{2}{|c|}{$\begin{array}{l}\text { Hosted family } \\
\text { w/ food insecurity }\end{array}$} & \multicolumn{2}{|c|}{$\begin{array}{l}\text { Hosted family } \\
\text { fleeing violence }\end{array}$} \\
\hline $\begin{array}{l}\text { Violence } \\
\text { index }(0-6)\end{array}$ & $\begin{array}{c}\mathbf{0 . 0 5}{ }^{* * *} \\
(0.01)\end{array}$ & $\begin{array}{c}\mathbf{0 . 0 5}{ }^{* * *} \\
(0.01)\end{array}$ & $\begin{array}{c}\mathbf{0 . 0 4}^{* * *} \\
(0.01)\end{array}$ & $\begin{array}{c}\mathbf{0 . 0 3}^{* * *} \\
(0.01)\end{array}$ & $\begin{array}{c}\mathbf{0 . 0 4}{ }^{* * *} \\
(0.01)\end{array}$ & $\begin{array}{c}\mathbf{0 . 0 4}^{* * * *} \\
(0.01)\end{array}$ \\
\hline $\mathrm{R}^{2}$ & 0.17 & 0.19 & 0.19 & 0.21 & 0.12 & 0.15 \\
\hline Num. obs. & 1070 & 1053 & 1070 & 1053 & 1070 & 1053 \\
\hline Y Mean & .39 & .39 & .53 & .53 & .28 & .28 \\
\hline Village FE & $\mathrm{Y}$ & $\mathrm{Y}$ & $\mathrm{Y}$ & $\mathrm{Y}$ & $\mathrm{Y}$ & $\mathrm{Y}$ \\
\hline Ctrl Vars & $\mathrm{N}$ & $\mathrm{Y}$ & $\mathrm{N}$ & $\mathrm{Y}$ & $\mathrm{N}$ & $\mathrm{Y}$ \\
\hline
\end{tabular}

Estimates of equation 2, along with its analog without control variables are presented for each outcome. The survey was updated part-way through the survey to include additional outcomes and covariates; sample sizes vary accordingly.

\section{Wartime violence and empathetic preferences}

Because empathy should increase responsiveness to signs of refugees' distress and reduce the relative importance of refugee identity, we expect violence-affected individuals to host a higher proportion of distressed and outgroup refugees. Table 3 presents the results of this analysis. Consistent with the empathy born of violence hypothesis, we see a large shift towards distressed refugees, as measured by having health problems at arrival, and towards refugee families that were fleeing direct violence. We do not see a significant shift towards food-insecure refugees, though the sign of the coefficient is in the expected direction. ${ }^{17}$

We also find that violence associates with hosting a greater proportion of non-coethnic

\footnotetext{
${ }^{17}$ This could also be due to lack of variation - 92 per cent of refugees families were described by their hosts as "very hungry" or "starving" upon arrival.
} 
Table 3: Wartime violence and the composition of hosted refugees

\begin{tabular}{|c|c|c|c|c|c|c|c|c|c|c|}
\hline \multirow[b]{2}{*}{$\begin{array}{l}\text { Violence } \\
\text { Index (0-6) }\end{array}$} & \multicolumn{2}{|c|}{$\begin{array}{l}\text { \% Refugee months } \\
\text { (not co-ethnic) }\end{array}$} & \multicolumn{2}{|c|}{$\begin{array}{l}\text { \% Refugee months } \\
\text { Muslim }\end{array}$} & \multicolumn{2}{|c|}{$\begin{array}{c}\% \text { of families } \\
\text { health problems }\end{array}$} & \multicolumn{2}{|c|}{$\begin{array}{l}\% \text { of families } \\
\text { food insecure }\end{array}$} & \multicolumn{2}{|c|}{$\begin{array}{c}\% \text { of families } \\
\text { fled direct violence }\end{array}$} \\
\hline & $\begin{array}{c}0.00 \\
(0.01)\end{array}$ & $\begin{array}{c}\mathbf{0 . 0 1}^{* *} \\
(0.01)\end{array}$ & $\begin{array}{c}\mathbf{0 . 0 1}^{* * *} \\
(0.00)\end{array}$ & $\begin{array}{c}\mathbf{0 . 0 1}^{* *} \\
(0.00)\end{array}$ & $\begin{array}{c}\mathbf{0 . 0 5}^{* * *} \\
(0.01)\end{array}$ & $\begin{array}{c}\mathbf{0 . 0 4}^{* * *} \\
(0.01)\end{array}$ & $\begin{array}{c}0.01 \\
(0.01)\end{array}$ & $\begin{array}{c}0.02 \\
(0.01)\end{array}$ & $\begin{array}{c}\mathbf{0 . 0 4}{ }^{* * *} \\
(0.01)\end{array}$ & $\begin{array}{c}\mathbf{0 . 0 4}^{* * *} \\
(0.01)\end{array}$ \\
\hline $\mathrm{R}^{2}$ & 0.33 & 0.44 & 0.19 & 0.22 & 0.13 & 0.15 & 0.15 & 0.16 & 0.13 & 0.15 \\
\hline Ctrl vars & $\mathrm{N}$ & $\mathrm{Y}$ & $\mathrm{N}$ & $\mathrm{Y}$ & $\mathrm{N}$ & $\mathrm{Y}$ & $\mathrm{N}$ & $\mathrm{Y}$ & $\mathrm{N}$ & Y \\
\hline Num. obs. & 745 & 734 & 745 & 734 & 763 & 752 & 763 & 752 & 763 & 752 \\
\hline
\end{tabular}

Estimates of equation 2, along with its analog without control variables are presented for each outcome. Outcomes are defined only for those who hosted refugees.

and non-coreligious refugee families. In particular, we find a unit increase in exposure to violence associates with a 1 percentage point increase in proportion of refugee families that are not co-ethnic and a 1 percentage point increase in the proportion of refugee families that were Muslim. Overall, these results are consistent with the hypothesis that violence strengthens empathetic preferences that in turn motivate helping behavior across group boundaries.

\section{Conjoint experiment}

To validate the results of the observational analysis, we turn to the conjoint experiment. Following the procedures outlined in Hainmueller et al. (2014), we estimate the probability that a hypothetical refugee family is hosted via:

$$
\begin{aligned}
\text { Hosted }_{i j k} & =\beta_{0}+\gamma_{1} \text { female }_{i k j}+\gamma_{2} \text { farmer }_{i k j}+\gamma_{3} \text { hunger }_{i k j} \\
& +\gamma_{4} \text { coethnic }_{i k j}+\gamma_{5} \text { coreligious }_{i k j}+\epsilon_{i}
\end{aligned}
$$


where $i$ denotes the respondent, $k$ the round or "choice task", and $j$ the depicted refugee family. In our experiment, $i \in\{1,2, \ldots, 1230\}, k \in\{1,2,3\}$, and $j \in\{1,2\}$. Note that each respondent $i$ yields 6 observations in this analysis: 3 rounds, and 2 choices per round. The unit of analysis is the hypothetical refugee family, the outcome is a binary indicator for whether the family is selected, and the explanatory variables are the family's attributes. Because each attribute is randomly assigned, equation (2) returns unbiased estimates of the average effect of each attribute on the probability that a refugee family is hosted. ${ }^{18}$ Standard errors are clustered by individual.

The upper-left panel of Figure 1 displays the average effect of each attribute on whether a refugee family is hosted (for results in Table form, see Appendix 5). Consistent with the region's long history of cross-border ethnic violence, discrimination against non-coreligious (i.e. Muslim) refugees is severe, with non-coreligious refugees 15 per cent less likely to be hosted than coreligious refugees. To a lesser degree, respondents prefer to host distressed (i.e. hungry) refugees, female-headed households, and refugees with farming skills.

Figure 1 also displays the marginal effects by Violvict graphically among those not primed prior to the experiment (as the prime may crowd-out response heterogeneity), showing that bias against non-coreligous refugees decreases with prior exposure to violence. To a lesser degree, Figure 1 shows that preferences for distressed (i.e. hungry) and vulnerable (i.e female) refugees also increases with prior exposure to violence, though these results are not statistically significant.

Figure 2 displays the results of the empathetic prime. In the control group, discrimination against non-coreligious refugees is the single strongest predictor of whether a refugee is hosted. However, when individuals consider their own experiences with violence and displacement prior to deciding who to host, they become significantly more responsive to signs

\footnotetext{
${ }^{18}$ With restricted randomization to exclude implausible profiles, the support from Ethnic Ingroup, Religious Outgroup comes from the subset of the ethnic groups for which this category exists.
} 


\section{Figure 1: Average Effects and Marginal Effects by Wartime Violence}
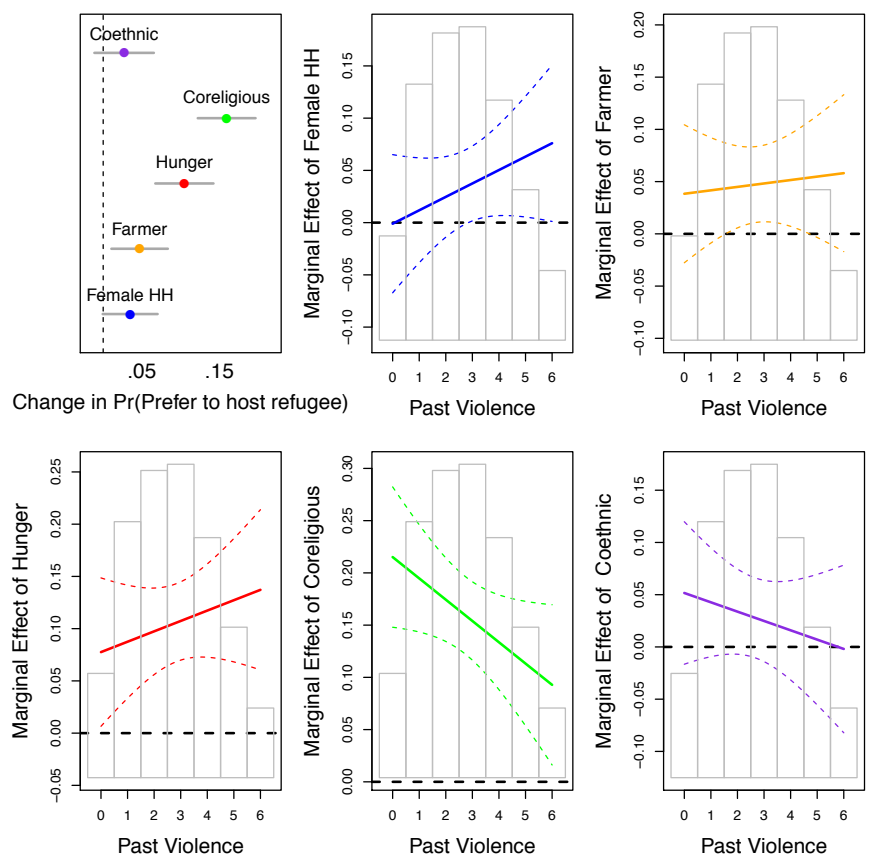

Estimated via OLS with standard errors clustered by individual; horizontal bars represent 95\% confidence intervals. The density of wartime violence exposure is displayed in the background.

of refugee distress, while bias against religious outgroups becomes significantly less severe. This result is consistent with those displayed in from Table 3 and Figure 1, and provides another piece of evidence in favor of the empathy born of violence hypothesis.

\section{Semi-structured interviews}

We find additional support for our argument in our field interviews with community leaders that we included as part of the data collection protocol in order to gather additional evidence on our hypotheses of interest and to gain a further understanding of the context where hosting took place. We asked community leaders to reflect on their personal reactions to the crisis as well as those of other community members. Analysis of these interviews suggests that individuals' past experiences with hardship during flight, exile and violence triggered an 


\section{Figure 2: Effect of Refugee Attributes on Whether Hosted}

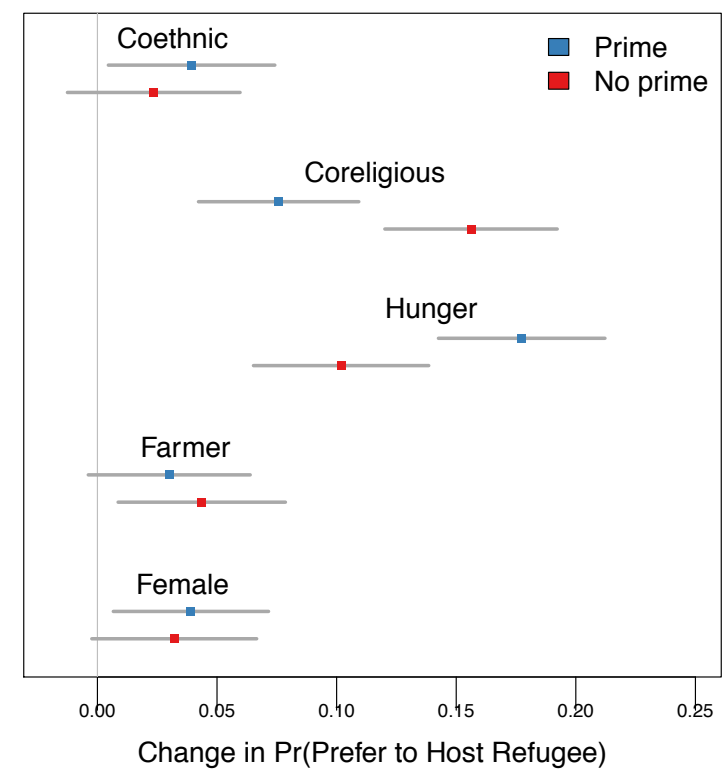

OLS estimates with standard errors clustered by individual; horizontal bars represent $95 \%$ confidence intervals.

empathetic response to the refugee crisis. Leaders commonly described experiences consistent with the three components of empathy, including 1) an emotional response to refugees' plight; 2) sympathy for refugees; and 3) reference to their own experience during the Liberian civil war in a way that suggests enhanced perspective taking and vicarious arousal.

First, leaders commonly related experiences of emotional distress during the refugee crisis. One leader explained that when we saw refugees he felt "sorrowful" and "mindful [of their] condition." 19 This reaction led members of the host communities to act. When asked why they hosted refugees, a leader explained that when he saw a refugees in distress, it was "impossible" to "pass by" the individual in need. ${ }^{20}$ Another explicitly linked feelings of sympathy to the motivation to host, stating: "If you go and find a group of people without shelter, with all of their possessions, near your house, it looks sorrowful. So you go there

\footnotetext{
${ }^{19}$ Interview, Nimba County, June 2014

${ }^{20}$ Interview, Nimba County, June 2014.
} 
and offer to host them and bring them to your house." 21

Leaders also described their decisions to host as specifically influenced by the recollection of their own experience during the Liberian civil war. For instance, when asked why Liberians hosted refugees, one leader stated "I recall what we experienced!" ${ }^{22}$ Another explained: "We know what it is to be a refugee ... when you are refugees you leave everything in your country ... so when someone is a refugee, you who pass through it before ... you know the pros and cons about it." 23

The shared experience of hardship also appears to have made it easier to identify with refugees regardless of their ethnic or religious backgrounds: "We Liberians, we experienced war. So when they say war drove them, when they talked about their problems, that the same thing happened to us Liberians before. So we embraced them." 24

\section{Robustness checks and consideration of alternative explanations}

In the above section, we provide support for the empathy born of violence hypothesis using two manipulations of our independent variable and three sets of outcomes - absolute levels of hosting, proportions of refugee-types hosted, and experimentally elicited preferences. We view the consistency of our findings across these tests, in tandem with supporting evidence from semi-structured interviews, as a compelling set of evidence in support of our argument.

Nevertheless, as with any study focused on intrinsic explanations of behavior, we cannot conclusively identify empathy as responsible for our results. Instead, following the advice of King et al. (1994), our approach has been to test as many observable implications of our argument as possible, leveraging the fact many of these implications are unique to the empathy born of violence hypothesis. In this section, we complement this approach with several robustness checks and a consideration of alternative explanations.

\footnotetext{
${ }^{21}$ Interview, Grand Gedeh, May 2014.

${ }^{22}$ Interview, Grand Gedeh, June 2014.

${ }^{23}$ Interview, Nimba County, May 2014.

${ }^{24}$ Interview, River Gee, June 2014.
} 


\section{Post-traumatic growth and prosociality}

The theory of post-traumatic growth theory posits a broad set of generalized changes in the aftermath of trauma, including new goals, improved interpersonal relationships, broader worldviews, greater activism, and a stronger social and prosocial orientation (Tedeschi and Calhoun 2004). Is it possible that our results might reflect these general improvements in social and prosocial behavior rather than empathy in particular?

Perhaps the strongest case against this possibility is that these changes cannot account for the patterns reported in Table 3 and Figures 1 and 2, which are uniquely consistent with a story in which violence strengthens empathetic motivations for hosting at the expense of identity considerations. It is, however, plausible that greater prosociality contributes to the aggregate hosting patterns reported in Table 2. To assess this possibility, we aggregate measures of prosocial behavior from our survey into an index of Prosociality. These include: contributions to public goods in community in the past 30 days, community group membership and meeting attendance. When included as a control in the context of equation (1), the effect of violence exposure on refugee hosting $(\gamma)$ is substantively unaffected. This result is consistent across all measures of hosting behavior included in Table 2 and 3 (Appendix 4). Following Imai et al. (2011), we interpret this as evidence against the argument that hosting behavior is driven by greater Prosociality in general.

\section{Social norms}

Theories of public goods provision in small groups emphasize the importance of social rewards and sanctions for motivating altruistic behavior (Ostrom 2000). In light of this literature, one might be concerned that social rewards or sanctions disproportionately targeted violenceaffected Liberians, driving them to host more refugees.

We find no evidence to support this hypothesis. In the 2014 survey, we asked whether the respondent found the refugee family on their own, whether an authority in the community facilitated hosting, and whether an authority or other community members pressured them 
to host. We find that for 93 per cent of refugee families, the host found them herself; only 5 per cent of families hosted were associated with pressure from village authorities and only 9 per cent of families hosted were associated with pressure from other community members. Further, we find no evidence that these pressures associate positively with past violence victimization (Appendix 4).

\section{Reciprocity}

Another potential explanation for our results derives from theories of reciprocity, which predict that those who are helped by others will feel intrinsically obligated to reciprocate in the future. If those who suffered violence during the war were also more likely to rely on Ivorians for assistance during the war, then it is possible that the positive association between violence and hosting is driven by norms of reciprocity rather than empathy.

We certainly do find evidence that norms of reciprocity may have influenced hosting behavior in general during the crisis - nearly three quarters of our sample reports that they lived abroad as refugees during the war, and 15 per cent reported hosting some of the same families during the crisis as once hosted them. However, we believe it is unlikely that a norm of reciprocity accounts for the association between violence and hosting behavior because empirically, violence does not correlate with having been a refugee (Appendix 4). In other words, those who experienced violence during the war were just as likely to have relied on Ivorians as those who did not experience violence, making it unlikely that they would have subsequently felt a stronger obligation to reciprocate during the Ivorian refugee crisis.

In addition, explanations rooted in theories of reciprocity can explain neither the positive association between violence and outgroup hosting nor the shift in preferences towards distressed refugees. Indeed, because the logic of reciprocity hinges on repeated interaction, norms of reciprocity are generally believed to operate within groups, particularly close-knit groups where repeated interaction is common (Ostrom 2000). This is certainly the case in our setting, where the vast majority of Liberians who were refugees in Côte d'Ivoire dur- 
ing the Liberian civil war relied on assistance from coethnic Ivorians. ${ }^{25}$ Hence, if violence influences hosting through reciprocity, we would expect it to associate with greater ingroup hosting. In fact we find the opposite: violence-affected Liberians host higher proportions of outgroup refugees - including Muslim refugees, who were coethnic their wartime rivals and, over the course of the 1990s, increasingly embroiled in a conflict with their 'native' hosts in Côte d'Ivoire. Violence-affected Liberians thus exhibited greater generosity towards precisely the kinds of refugees who would have been the least likely to have offered them support in the past. ${ }^{26}$

\section{Selective migration}

Another concern is selective migration. While this concern does not apply to the priming experiment, it does apply to the observational analysis, where it would confound if those disinclined toward altruistic behavior and victimized by violence were disproportionately likely to permanently flee the villages in our sample. Though we cannot observe those who fled during the war, we can assess whether our results hold among those who were born in the community in which we surveyed them - a sample where concerns about selective migration do not apply. Appendix 4 shows that the results do not change when we subset to this sample. In tandem with their consistency with the results from the empathetic prime, these results suggest that selective migration is unlikely to confound our analysis. Another reason this seems unlikely is that the correlation between violence and migration between

\footnotetext{
${ }^{25}$ Of the 75 per cent of respondents that report having been a refugee in Côte d'Ivoire during the Liberian civil war, 73 per cent report that they spent most of their time with a coethnic host family (as compared to a refugee camp (15 per cent) or non-coethnic family (11 per cent)).

${ }^{26}$ The same reasoning suggests its also unlikely that violence-affected Liberians hosted more diverse refugees out of desire to establish reciprocal relationships on which to draw in the event of a return to war in Liberia, since outgroup refugees are least likely to be in a position to reciprocate during periods of intergroup conflict.
} 
villages is only .02 , and not statistically significant. ${ }^{27}$

\section{Validity of the empathetic prime}

Our approach to priming empathy is similar to those employed in psychology, where researchers have sought to prime empathy by asking subjects to either write an essay considering the perspective of another (Galinsky and Moskowitz 2000), reflect on their own experiences with hardship (Staub and Vollhardt 2008), or consider their own feelings and emotions while evaluating the position of a disadvantaged other (Esses and Dovidio 2002). However, as with all experiments aimed at manipulating subjects' internal mental processes, it is impossible to know for sure that our empathetic prime indeed worked as intended. Perhaps the priming experiment actually primes something other than empathy, such as reciprocity or fear. Though we cannot rule this out entirely, neither fear nor reciprocity strike us as plausible, since these emotions tend to associate with ingroup rather than outgroup attachment. In our view, the fact that the results of the experiment adhere so closely to the predictions of empathy (i.e. strengthened preferences for refugees in distress and lower bias against outgroup refugees) is the most compelling reason to believe our prime worked as intended - given this pattern of results, what other explanations are plausible?

\section{Generalizability}

Whether the link between violence, empathy, and intergroup altruism holds outside the context of our study is an outstanding question. While we view this as an important avenue for future research, we offer two reasons to suspect it might. For one, our findings are in-line with the broader literature on post-traumatic growth after violence. As discussed Section 2, we suspect empathy born of violence may contribute to these broader patterns of growth

\footnotetext{
${ }^{27}$ This result also holds using data from Blattman et al. (2014), which covers a much larger sample of towns and villages in our study region (a more detailed description of these data follows below).
} 
after violence.

Another reason we believe our results may generalize is that we also observe a positive association between violence and charitable behavior is also observed when analyzing intergroup behavior within Liberian towns and villages. We show this using data from the same region collected in 2009 and 2010 by Blattman et al. (2014), which includes information on religion, ethnicity, wartime violence experiences, and charity toward families that were sick in the past month, and covers large sample of 242 towns and villages. We find that wartime violence is linked to greater charity and that this effect is equally strong in diverse villages. Full details are provided in Appendix 4. This result suggests the relationship between violence exposure and greater altruism toward ingroup and outgroups may generalize beyond the Ivorian refugee crisis. Nevertheless, moving forward further research will be required to understand conditions under which violence can promote prosocial behavior through its impact on empathy.

\section{Other Limitations}

We study hosting behavior in a setting where refugees are similar to their host in terms of their economic, cultural, and social backgrounds. We view this as a strength of our study insofar as culturally-close relations characterize the majority of interactions between the forcibly displaced and their hosts (given most flee within their own country or to neighboring countries). But it also raises the question of whether our results extend to refugee-host interactions in developed countries, where refugees may be less familiar with the cultural practices of their hosts and less able to integrate economically. While developed countries host only fourteen per cent of the world's refugees (and an even smaller fraction of the world's forcibly displace) (UNHCR 2016), this nevertheless remains an important and largely outstanding question.

Another limitation of our study is that it does not speak to the limits of empathy born of violence. It is plausible, for instance, that empathey fades overtime until a point where 
it no longer offsets the burden of hosting, leading to a breakdown in hosts' generosity. Our study cannot speak to this possibility because we do not have panel data on hosts' levels of empathy during the course of the crisis, and more generally, because there are a wide variety of factors that influence how long refugees stay with their hosts. Understanding the limits of empathy born of violence therefore constitutes an important topic for further research.

\section{Conclusion}

This paper hypothesized that empathy born of violence can motivate altruistic behavior across group boundaries. To test this argument, we examined the association between Liberians' past experiences with violence and their support refugees during the 2010-11 Ivorian refugee crisis, showing that those who directly or indirectly suffered violence in the past host more refugees overall, exhibit stronger preferences for distressed refugees and less bias against outgroup refugees, and host a higher proportion of non-coethnic, non-coreligious and distressed refugees.

In highlighting empathy as mechanism linking violence to prosocial behavior across group boundaries, we make two contributions to existing theory. First, we distinguish empathy from the broader set of changes enumerated by post-traumatic growth theory (PTGT). Whereas PTGT is vague about the mechanisms linking trauma to prosocial behavior and silent about how they influence behavior toward outgroups, our theory of empathy born of violence is not. Rooted in the shared experience of hardship, empathy born of violence can transcend identity boundaries and motivate altruistic behavior across group boundaries, even in the poorest regions of the world with histories of extreme intergroup violence.

Our second theoretical contribution relates to the conditions under which the legacies of violence are more or less likely to be parochial. Though our findings depart from conventional arguments emphasizing the parochial effects of violence, we stress that the two perspectives are not mutually exclusive. On the contrary, together they highlight how vio- 
lence may simultaneously influence the motivations for prosocial behavior in ways that are both parochial and bridging. Violence may, for example, strengthen norms of ingroup solidarity and harden attitudes toward rival groups, even as it enhances empathetic capacity. An important implication of this reasoning is that identifying mechanisms and considering how they interact with context is essential when trying to understand how violence might influence behavior in a given setting. For example, we suspect that the legacy of violence is more likely to be "bridging" in settings where empathetic motivations for behavior are salient (e.g. decisions to help those in need, decisions to (not) harm others (Hazlett 2015)), but that it may well be parochial in other settings (e.g. competition over power or resources in post-conflict settings). This is speculation, of course, and we leave it to future research to uncover whether and why the legacy of violence on intergroup behavior varies across settings.

Finally, our results are of practical import for policymakers. According to the UNHCR, 2016 saw the highest number of people displaced by violence ever recorded. Yet the sources of support (or lack thereof) for those fleeing violence remain poorly understood. Our findings suggest past experiences with violence do not necessarily undercut support for refugees even when they come from antagonistic groups — and that it may instead be an important source of support. While survivors of violence and hardship should not be expected to bear a disproportionate share of burden of hosting refugees, empathetic appeals targeted toward the host population generally may be an effective means cultivate support for the world's most vulnerable.

\section{References}

Adida, C. L. (2014). Immigrant exclusion and insecurity in Africa. Cambridge University Press.

Balcells, L. and A. Steele (2016). Warfare, political identities, and displacement in spain and colombia. Political Geography 51, 15-29. 
Bansak, K., J. Hainmueller, and D. Hangartner (2016). How economic, humanitarian, and religious concerns shape european attitudes toward asylum seekers. Science 354(6309), $217-222$.

Bateson, R. (2012). Crime victimization and political participation. American Political Science Review 106 (03), 570-587.

Batson, C. D. and K. C. Oleson (1991). Current status of the empathy-altruism hypothesis.

Batson, C. D. and A. A. Powell (2003). Altruism and prosocial behavior. Handbook of psychology.

Batson, D. e. a. (1997). Empathy and attitudes: Can feeling for a member of a stigmatized group improve feelings toward the group? Journal of personality and social psychology 72(1), 105.

Bauer, M., C. Blattman, J. Chytilova, J. Henrich, E. Miguel, and T. Mitts (2016). Civil war and social cohesion: Lab-in-the-field evidence from nepal. Journal of Economic Perspectives.

Bauer, M., A. Cassar, J. Chytilová, and J. Henrich (2013). War's enduring effects on the development of egalitarian motivations and in-group biases. Psychological science, 0956797613493444 .

Bauer, M., A. Cassar, J. Chytilová, and J. Henrich (2014). Wars enduring effects on the development of egalitarian motivations and in-group biases. Psychological science 25(1), $47-57$.

Beber, B., P. Roessler, and A. Scacco (2014). Intergroup violence and political attitudes: evidence from a dividing sudan. Journal of Politics 76 (3), 649-65.

Bellows, J. and E. Miguel (2009). War and local collective action in sierra leone. Journal of Public Economics 93(11), 1144-1157.

Berry, L. (2008). The impacts of environmental degradation on refugee?host relationships. African Security Studies 17(3), 125-131.

Betts, A. and P. Collier (2017, March). Refuge: Transforming a Broken Refugee System. 
London: Allen Lane.

Blattman, C. (2009). From violence to voting: War and political participation in uganda. American Political Science Review 103(2), 231-247.

Blattman, C., A. Hartman, and R. Blair (2014). How to promote order and property rights under weak rule of law? an experiment in changing dispute resolution behavior through community education. American Political Science Review 108(1), 100-120.

Brader, T., N. A. Valentino, and E. Suhay (2008). What triggers public opposition to immigration? anxiety, group cues, and immigration threat. American Journal of Political Science 52(4), 959-978.

Brady, C. e. a. (2012). An emergency market mapping and analysis study: Liberia's slow onset crisis. Oxfam Policy and Practice: Agriculture, Food and Land 12(1), 230245.

Calhoun, L. G. and R. G. Tedeschi (2014). Handbook of posttraumatic growth: Research and practice. Routledge.

De Waal, F. B. (2008). Putting the altruism back into altruism: the evolution of empathy. Annu. Rev. Psychol. 59, 279-300.

Dovidio, J. F. (1984). Helping behavior and altruism: An empirical and conceptual overview. Advances in experimental social psychology 17, 361-427.

Dunning, T. and L. Harrison (2010). Cross-cutting cleavages and ethnic voting: An experimental study of cousinage in mali. American Political Science Review 104(01), 21-39.

Eisenberg, N. (2000). Emotion, regulation, and moral development. Annual review of psychology 51(1), 665-697.

Ellis, S. (2001). The mask of anarchy: the destruction of Liberia and the religious dimension of an African civil war. NYU Press.

Esses, V. M. and J. F. Dovidio (2002). The role of emotions in determining willingness to engage in intergroup contact. Personality and Social Psychology Bulletin 28(9), 12021214 .

Forbes, H. D. (1997). Ethnic conflict: Commerce, culture, and the contact hypothesis. Yale 
University Press.

Galinsky, A. D. and G. B. Moskowitz (2000). Perspective-taking: decreasing stereotype expression, stereotype accessibility, and in-group favoritism. Journal of personality and social psychology 78(4), 708.

Gleditsch, K. and I. Salehyan (2006). Refugees and the spread of civil war. International Organization 60(2), 335-366.

Hainmueller, J., D. Hopkins, and T. Yamamoto (2014). Causal inference in conjoint analysis: Understanding multi-dimensional choices via stated preference experiments. Political Analysis.

Harild, N., P. Vinck, S. Vedsted, and J. de Berry (2013). Forced displacement of and potential solutions for idps and refugees in the sahel - burkina faso, chad, mali, mauritania \& niger. Global Program on Forced Displacement.

Hazlett, C. (2015). Angry or weary? the effect of physical violence on attitudes towards peace in darfur. Unpublished Working Paper.

Hjort, J. (2014). Ethnic divisions and production in firms. 129(04), 1899-1946.

ICG, I. C. G. (2003). Tackling Liberia: The Eye of the Regional Storm. Number 62. International Crisis Group.

ICG, I. C. G. (2010). Côte d'Ivoire: Securing the Electoral Process. Number 158. International Crisis Group.

Imai, K., L. Keele, D. Tingley, and T. Yamamoto (2011). Unpacking the black box of causality: Learning about causal mechanisms from experimental and observational studies. American Political Science Review 105(4), 765-789.

Imbens, G. W. (2003). Sensitivity to exogeneity assumptions in program evaluation. The American Economic Review 93(2), 126-132.

Karylowski, J. (1976). Self-esteem, similarity, liking and helping. Personality and Social Psychology Bulletin 2(1), 71-74.

Kijewski, S. and M. Freitag (2016, September). Civil War and the Formation of Social 
Trust in Kosovo: Posttraumatic Growth or War-related Distress? Journal of Conflict Resolution, 0022002716666324.

King, G., R. O. Keohane, and S. Verba (1994). Designing social inquiry: Scientific inference in qualitative research. Princeton university press.

Klaas, B. (2008). From miracle to nightmare: an institutional analysis of development failures in cote d'ivoire. Africa Today 55(1), 109-126.

Krebs, D. (1975). Empathy and altruism. Journal of Personality and Social psychology 32(6), 1134.

Levitt, S. D. and J. A. List (2007). What do laboratory experiments measuring social preferences reveal about the real world? The journal of economic perspectives, 153-174.

Li, Y., H. Li, J. Decety, and K. Lee (2013, September). Experiencing a Natural Disaster Alters Childrens Altruistic Giving. Psychological Science 24(9), 1686-1695.

Lidow, N. H. (2011). Violent Order: Rebel Organization and Liberia's Civil War. Stanford University.

McCauley, J. F. (2013). Economic development strategies and communal violence in africa the cases of côte divoire and ghana. Comparative Political Studies 46(2), 182-211.

McGovern, M. (2011). Making war in Côte d'Ivoire. University of Chicago Press Chicago.

Mironova, V. and S. Whitt (2016, September). The evolution of prosociality and parochialism after violence. Journal of Peace Research 53(5), 648-664.

Oster, E. (2017). Unobservable selection and coefficient stability: Theory and evidence. Journal of Business Economics and Statistics.

Ostrom, E. (1996). Crossing the great divide: coproduction, synergy, and development. World development 24(6), 1073-1087.

Ostrom, E. (2000). Collective action and the evolution of social norms. The Journal of Economic Perspectives, 137-158.

Petersen, R. D. (2011). Western intervention in the Balkans: the strategic use of emotion in conflict. Cambridge University Press. 
Polzer, T. (2009). Negotiating Rights: Th e Politics of Local Integration. Refuge: Canada's Journal on Refugees 26(2).

Posen, B. R. (1993). The security dilemma and ethnic conflict. Survival 35(1), 27-47.

Rohner, D., M. Thoenig, and F. Zilibotti (2013). Seeds of distrust: Conflict in uganda. Journal of Economic Growth 18(3), 217-252.

Rozenas, A., S. Schutte, and Y. Zhukov (2017). The Political Legacy of Violence: The Long-Term Impact of Stalin's Repression in Ukraine. Journal of Politics Forthcoming.

Ruttan, R. L., M. H. McDonnell, and L. F. Nordgren (2015, April). Having "been there" doesn't mean i care: When prior experience reduces compassion for emotional distress. Journal of Personality and Social Psychology 108(4), 610-622.

Sambanis, N. and M. Shayo (2013). Social identification and ethnic conflict. American Political Science Review 107(02), 294-325.

Scott, J. C. (1977). The moral economy of the peasant: Rebellion and subsistence in Southeast Asia. Yale University Press.

Shechter, H. and G. Salomon (2005). Does vicarious experience of suffering affect empathy for an adversary? the effects of israelis visits to auschwitz on their empathy for palestinians. Journal of Peace Education 2(2), 125-138.

Staub, E. and J. Vollhardt (2008). Altruism born of suffering: The roots of caring and helping after victimization and other trauma. American Journal of Orthopsychiatry 78(3), 267280.

Sturridge, C. (2011). The impacts of environmental degradation on refugee?host relationships. New Issues in Refugee Research Research Papers (204).

Tedeschi, R. G. and L. G. Calhoun (2004). Posttraumatic growth: Conceptual foundations and empirical evidence. Psychological inquiry 15(1), 1-18.

UNHCR (2013). The benefits of belonging: Local integration options and opportunities for host countries, communities and refugees. UNHCR Policy Document.

UNHCR (2016). Global trends: Forced displacement in 2015. UNHCR Policy Document. 
Voors, M., T. Turley, A. Kontoleon, E. Bulte, and J. A. List (2012). Exploring whether behavior in context-free experiments is predictive of behavior in the field: Evidence from lab and field experiments in rural sierra leone. Economics Letters 114(3), 308-311.

Voors, M. J., E. E. Nillesen, P. Verwimp, E. H. Bulte, R. Lensink, and D. P. Van Soest (2012). Violent conflict and behavior: a field experiment in burundi. The American Economic Review 102(2), 941-964.

Whitaker, B. E. (2003). Refugees and the spread of conflict: Contrasting cases in central africa. Journal of Asian and African Studies 38(2-3), 211-231.

Wong, P.-H. (2016, November). How can political trust be built after civil wars? Evidence from post-conflict Sierra Leone. Journal of Peace Research 53(6), 772-785.

Zeitzoff, T. (2016, June). Anger, legacies of violence, and group conflict: An experiment in post-riot Acre, Israel. Conflict Management and Peace Science, 0738894216647901. 